\title{
Predictive and Prognostic Value of Von Willebrand Factor in Patients with Cirrhosis and Esophageal Varices
}

\author{
Naglaa El-Toukhy ${ }^{1}$ and Hisham Issa ${ }^{2}$ \\ ${ }^{1}$ Department of Hepatology, Gastroenterology and Infectious Diseases, Faculty of Medicine, \\ Benha University, Egypt \\ ${ }^{2}$ Department of Clinical pathology, Faculty of Medicine, Benha University, Egypt.
}

Corresponding Author Naglaa El-Toukhy

Mobile:

01224720998

E mail: naglaaeltoukhy@yaho o.com

Key words: vWF; Cirrhosis; esophageal Varices
Background and study aim: Von Willebrand factor (vWF) is released by activated endothelial cells and plays a crucial role in the development of portal hypertension. vWF levels correlate with liver function and venous hepatic pressure gradient (VHPG) and independently predict clinical outcome. The aim was to evaluate serum vWF levels as a predictor for esophageal varices and prognosis in patients with liver cirrhosis.

Patients and Methods: Sixty two patients with liver cirrhosis, divided into two groups according to presence (group I) or absence (group II) of varices were included, In addition, twenty healthy persons served as control group (group III). All patients were submitted to full history taking, clinical examination, laboratory investigations and abdominal ultrasonography. The severity of liver disease was estimated by Modified Child-Pugh and Model for End Stage Liver Disease (MELD) scores. All patients

\section{INTRODUCTION}

Clinically, cirrhosis has been regarded as an end-stage disease that invariably leads to death. Unless liver transplantation is done, the only preventive strategies available are the screening for early detection of esophageal varices and hepatocellular carcinoma. Lately, this perception has been challenged, because 1-year mortality in cirrhosis varies widely, from $1 \%$ to $57 \%$, depending on the occurrence of clinical decompensating events [1].

Portal hypertension $(\mathrm{PH})$ accounts for the major complications of liver cirrhosis, such as ascites, variceal hemorrhage and decompensation. Early diagnosis of $\mathrm{PH}$ is essential for the management of patients with cirrhosis. were underwent upper gastrointestinal endoscopy and vWF assay.

Results: vWF values were significantly higher in group I ( $1=0.001)$, than controls (p2=0.000), but no significant difference between group II and control group (p3= 0.59 ). Receiver operating characteristics (ROC) curve analysis of $\mathrm{vWF}$ revealed that, vWF at cutoff value of $173.8 \mu \mathrm{g} / \mathrm{ml}$; the sensitivity for detection of esophageal varices was $80.8 \%$, specificity $76.0 \%$, positive predictive value (PPV) was $93.9 \%$, negative predictive value (NPV) was $55.6 \%$; area under the curve was 86.6.There was significant positive correlation between vWF and Child, MELD, esophageal varices grade and severity of portal hypertensive gastropathy.

Conclusion: vWF is a good predictor for development of esophageal varices and correlated well with prognosis in patients with cirrhosis.
In previous studies, it has been shown that early diagnosis, leading to adequate treatment, can significantly reduce the mortality rate of $\mathrm{PH}$-related complications $[2,3]$. Endothelial dysfunction is considered as an important determinant of the increased intrahepatic vascular resistance in cirrhotic livers [4].

Von Willebrand factor is a large adhesive protein released by activated endothelial cells and represents an indicator of endothelial cell activation [5].VWF is a noninvasive predictor of portal hypertension, esophageal varices and portal hypertensive gastropahty (PHG) in patients with cirrhosis. Increased levels of vWF in liver tissues may lead to the elevation of vWF in plasma [6]. vWF increases with every 
Child-Pugh stage. As vWF is a valuable noninvasive marker in patients with liver cirrhosis [7]. So, the aim of this study was to evaluate the predictive power of serum levels of vWF in patients with cirrhosis and esophageal varices.

\section{PATIENTS AND METHODS}

Patients. This is a case control study which was carried out on eighty-two subjects. Sixty-two patients with liver cirrhosis were divided into two groups according to presence (group I) or absence (group II) of esophageal varices attended or admitted to Hepatology, Gastroenterology and Infectious Diseases Department, Benha University Hospital, within the period between January and May 2016, after approval by the scientific committee of Benha Faculty of Medicine, in addition to twenty persons served as control group (group III).

Patients with cirrhosis were diagnosed by clinical manifestations, laboratory investigations and ultrasonography. Patients were classified according to presence or absence of varices which was diagnosed by upper gastrointestinal endoscopy. Patients with congestive heart failure, renal failure, lung disease, malignancy, hepatic encephalopathy, gastrointestinal bleeding, portal vein thrombosis, pregnancy, transjagular intrahepatic portosystemic shunt (TIPS), cholestatic liver disease, treatment with vasoactive drugs (beta-blockers), statin, aspirin, antioxidants in previous two weeks were excluded from this work at the time of study

Methods. All patients were subjected to full history taking thorough clinical examination and routine laboratory tests including liver biochemical profile as serum bilirubin (total, direct), serum albumin, prothrombin time, international normalized ratio and serum creatinine, viral markers: Hepatitis $\mathrm{C}$ virus antibody (HCVAb) and Hepatitis B virus surface antigen (HBsAg). Each patient was assigned a score and a grade reflecting the severity of liver affection according to:

- The numerical system of Child Turcotte Pugh (CTP) [8].

- MELD score (Model for End Stage Liver Disease) [9].

Von Willebrand factor was measured in serum of all subjects using Human von Willebrand factor (vWF) ELISA Kit.
Pelvi-abdominal ultrasonography was done using (LOGIC LG) with a convex probe (3.75 MHZ) for evaluation of liver, portal vein, presence of focal lesion), evaluation of spleen (size and echopattern) and the presence of ascites.

Esophagogastroduodenoscopy was done using disinfected upper gastrointestinal video scope (OLYMPUS model) after good preparation of the patient. Complete evaluation of the esophagus, stomach and the duodenum down to the second part of the duodenum. Esophageal varices were classified as small or large [10].

- Small esophageal varices were defined as: Varices that flatten with insufflation or minimally protrude into the esophageal lumen.

- While large esophageal varices were defined as: Varices that protrude into the esophageal lumen and touch each other (presence of confluence), or that fill at least $50 \%$ of the esophageal lumen.

The grading (I-IV) classification:

- Grades and were reclassified as small and

- Grades and V were reclassified as large for this study.

PHG were reported according to Modified grading system proposed by the Baveno III meeting (Baveno, Italy, 2000) on portal hypertension [11]

- PHG is mild when a pink mosaic-like mucosal pattern with no red signs or black-brown spots is present.

- PHG is severe when the mosaic-like mucosal pattern is red and superimposed by any red sign (red point lesions and/or cherry-red spots) or black-brown spots.

\section{Statistical Analysis:}

Statistical package for social sciences (SPSS, version 20.0) was used for data management (SPSS Inc., USA). Descriptive statistics was presented as mean \pm standard deviations for continuous variables, number and percentage for categorical variables (frequency distribution). Unpaired Student t-test (two sided) was used to test the significance of difference between the mean value of studied groups and Chi-square (X2) test was used for comparison of categorical variables. Pearson correlation test was used to identify the correlation between vWF and different variables. Receiver operative curve (ROC) was plotted to measure the diagnostic accuracy of vWF. P value $\leq 0.05$ was considered significant for interpretation of data. 


\section{RESULTS}

\section{Characteristics of the studied patients}

Sixty two patients with liver cirrhosis were included in this study. The cases were divided into two groups according to presence or absence of esophageal varices (OV), cases with esophageal varices (group 1) were fifty three while the other nine cases had no varices (group 2). The mean age was 55.6 \pm 7.6 in patients of (group 1) compared to 54.5 \pm 6.1 in patients of (group 2). There was no statistically significant difference between groups as regards to the age. The varices were more common in males than females (males were 42 cases and females were 11cases) (Table 1).

There was no statistical significant difference between the studied groups as regards the frequencies of $\mathrm{HCV}$ and $\mathrm{HBV}$ infections. Most cases of group were in advanced Child grade, when compared to cases group with statistical significance.

MELD score was significantly higher in group I, when compared to group II. By ultrasonography; Ascites, collaterals and periportal fibrosis (PPF) were predominate in group I with statistical significance (Table 1).

\section{Endoscopic findings}

In the present study, sixty two cases with liver cirrhosis were included; fifty three of them
(85.5\%) had esophageal varices and nine patients $(14.5 \%)$ had no esophageal varices. Portal hypertensive gastropathy (PHG) was predominant in group I with significant difference. The most of OV cases were OV grade III (Table 2).

\section{Serum vWF values in the studied groups}

Concerning Serum vWF value, it was significantly higher in group I $(330.5) \mathrm{pg} / \mathrm{ml}(\mathrm{p} 1=0.001)$, than in group II (155) $\mathrm{pg} / \mathrm{ml}$, higher in group I than controls $(155) \mathrm{pg} / \mathrm{ml}(\mathrm{p} 2=0.000)$, but no significant difference between group II and control group (p3=0.59) (Table 3).

\section{Serum vWF as a predictor for esophageal varices \\ Concerning $\mathrm{vWF}$ as a predictor for esophageal varices at cutoff value of $173.8 \mu \mathrm{g} / \mathrm{ml}$; the sensitivity for detection of esophageal varices was $80.8 \%$, specificity $76.0 \%$, positive predictive value (PPV) was 93.9\%, negative predictive value (NPV) was $55.6 \%$; area under the curve was 86.6 denoting good prediction of vWF in prediction of esophageal varices (Table 4 and Figure1).}

\section{vWF and severity of liver disease}

There was significant positive correlation between vWF and Child score, MELD score, OV grade and PHG severity (Table 5).

Table (1): Demographic features of the studied patient groups

\begin{tabular}{|l|c|c|c|}
\hline \multicolumn{1}{|c|}{ Characteristics } & $\begin{array}{c}\text { Group I (patients with OV) } \\
\text { N = 53 (85.5\%) }\end{array}$ & $\begin{array}{c}\text { Group II (Patients without } \\
\text { OV)N=9(14.5\%) }\end{array}$ & P. value \\
\hline \hline Age (years) & $33-67$ & $43-66$ & \\
Range & $55.6 \pm 7.6$ & $54.5 \pm 6.1$ & 0.68 \\
Mean \pm SD & & & \\
Gender & $42(79.2 \%)$ & $4(44.4 \%)$ & $0.042 *$ \\
Male & $11(20.8 \%)$ & $5(55.6 \%)$ & \\
Female & & & \\
Occupation & $16(30.2 \%)$ & $0(0.0 \%)$ & 0.064 \\
Farmer & $37(69.8 \%)$ & $9(100 \%)$ & \\
Non- farmer & & & 0.525 \\
Etiology & $49(92.5 \%)$ & $9(100 \%)$ & 0.855 \\
HCV & $1(1.9 \%)$ & $0(0.0 \%)$ & 0.464 \\
HBV & $3(5.7 \%)$ & $0(0.0 \%)$ & \\
Negative HCV, HBV & & & $0.001 *$ \\
Child- Pugh & $18(34.0 \%)$ & $9(100 \%)$ & \\
Child A & & & \\
\hline
\end{tabular}

El-Toukhy and Issa , Afro-Egypt J Infect Endem Dis 2019; 9(1):67-73

https://aeji.journals.ekb.eg/

http://mis.zu.edu.eg/ajied/home.aspx 


\begin{tabular}{|l|c|c|c|}
\hline Child B & $23(43.4 \%)$ & $0(0.0 \%)$ & $0.000^{*}$ \\
Child C & $12(22.6 \%)$ & $0(0.0 \%)$ & $0.000^{*}$ \\
MELD Score & & & \\
& $13.5 \pm 3.7$ & $9.6 \pm 2.3$ & $0.04^{*}$ \\
Ultrasound & & & \\
Spleen size & $15.2 \pm 5.8$ & $11.5 \pm 4.9$ & 0.079 \\
PV (cm) & $13.3 \pm 2.5$ & $12.2 \pm 1.4$ & 0.217 \\
Ascites & $26(49.1 \%)$ & $0(0.0 \%)$ & $0.005^{*}$ \\
Collaterals & $43(81.1 \%)$ & $2(22.2 \%)$ & $0.001^{*}$ \\
PPF & $51(96.2 \%)$ & $5(55.6 \%)$ & $0.003^{*}$ \\
\hline
\end{tabular}

OV, esophageal varices; SD, Standard deviation; HCV, hepatitis c virus; HBV, hepatitis B virus; MELD, Model for end stage liver disease; PV, portal vein; *, Significant; PPF, periportal fibrosis.

Table (2): Endoscopic features of the studied patients

\begin{tabular}{|l|c|c|c|c|c|}
\hline \multirow{2}{*}{ Variables } & \multicolumn{2}{|c|}{$\begin{array}{c}\text { Group I (patients with OV) } \\
\text { N = 53 (85.5\%) }\end{array}$} & $\begin{array}{c}\text { Group II (Patients without OV) } \\
\text { N=9(14.5\%) }\end{array}$ & \multirow{2}{*}{ P-value } \\
\cline { 2 - 5 } & $\mathrm{N}$ & $\%$ & $\mathrm{~N}$ & $\%$ & \\
\hline Varices grade & & & & & \\
Grade I & 11 & 20.8 & & & \\
Grade II & 17 & 32.1 & & & \\
Grade III & 19 & 35.8 & & & \\
Grade IV & 6 & 11.3 & & & \\
Gastric varices & 3 & 5.7 & 0.0 & 0.0 & \\
PHG & 19 & 35.8 & 8 & 88.9 & 0.619 \\
No & 23 & 43.4 & 0 & 0 & $0.01 \%$ \\
Mild & 11 & 20.8 & 1 & 11.1 & $0.022^{*}$ \\
Severe & & & & & \\
\hline
\end{tabular}

PHG, portal hypertensive gastropathy;*, significant

Table (3): Values of vWF among the studied groups

\begin{tabular}{|l|c|c|c|c|c|c|c|}
\hline & \multicolumn{2}{|c|}{$\begin{array}{c}\text { Group I (patients } \\
\text { with OV) } \\
\text { N=53(85.5\%) }\end{array}$} & \multicolumn{2}{|c|}{$\begin{array}{c}\text { Group II (Patients } \\
\text { without OV) } \\
\text { N=9(14.5\%) }\end{array}$} & \multicolumn{2}{|c|}{$\begin{array}{c}\text { Group III } \\
\text { (control group) } \\
\text { N= 20 }\end{array}$} & \multirow{2}{*}{ P value } \\
\cline { 2 - 6 } & Range & Mean \pm SD & Range & Mean \pm SD & Range & Mean \pm SD & \\
\hline & & & & & & & P1 $=0.001^{*}$ \\
$\mathrm{vWF}$ & $25.7-$ & $330.5 \pm$ & $67.7-$ & $155 \pm$ & $17.2-$ & $123.5 \pm$ & $\mathrm{P} 2=0.000^{*}$ \\
$(\mu \mathrm{g} / \mathrm{ml})$ & 616.8 & 155.78 & 271.2 & 82.4 & 312 & 96.6 & $\mathrm{P} 3=0.59$ \\
\hline
\end{tabular}

vWF, Von Willebrand factor; OV, esophageal varices; *, Significant; SD, Standard deviation.

$\mathrm{P} 1$ = comparison between group I and II; P2= comparison between group I and control group; P3= comparison between group II and control group.

Table (4): vWF as a predictor for esophageal varices

\begin{tabular}{|l|c|c|c|c|c|c|c|}
\hline \multicolumn{1}{|c|}{ Test } & Cutoff & Sensitivity \% & Specificity \% & PPV\% & NPV \% & AUC & P value \\
\hline $\begin{array}{l}\mathrm{vWF} \\
(\mu \mathrm{g} / \mathrm{ml})\end{array}$ & 173.8 & 80.8 & 76 & 93.9 & 55.6 & 86.6 & $0.000^{*}$ \\
\hline
\end{tabular}

* Significant; PPV, Positive predictive value; NPV, Negative predictive valu; AUC, Area under curve. 
Table (5): Correlations between vWF and different parameters in the studied patients

\begin{tabular}{|l|l|l|}
\hline vWF & Pearson correlation & P-value \\
\hline Child Score & 0.9 & $0.000^{*}$ \\
MELD & 0.64 & $0.000^{*}$ \\
Varices grade & 0.4 & $0.001^{*}$ \\
PHG garde & 0.309 & $0.015^{*}$ \\
\hline
\end{tabular}

vWF, von Willebrand factor; * , significant; PHG, portal hypertensive gastropathy; MELD, Model for end stage liver disease.

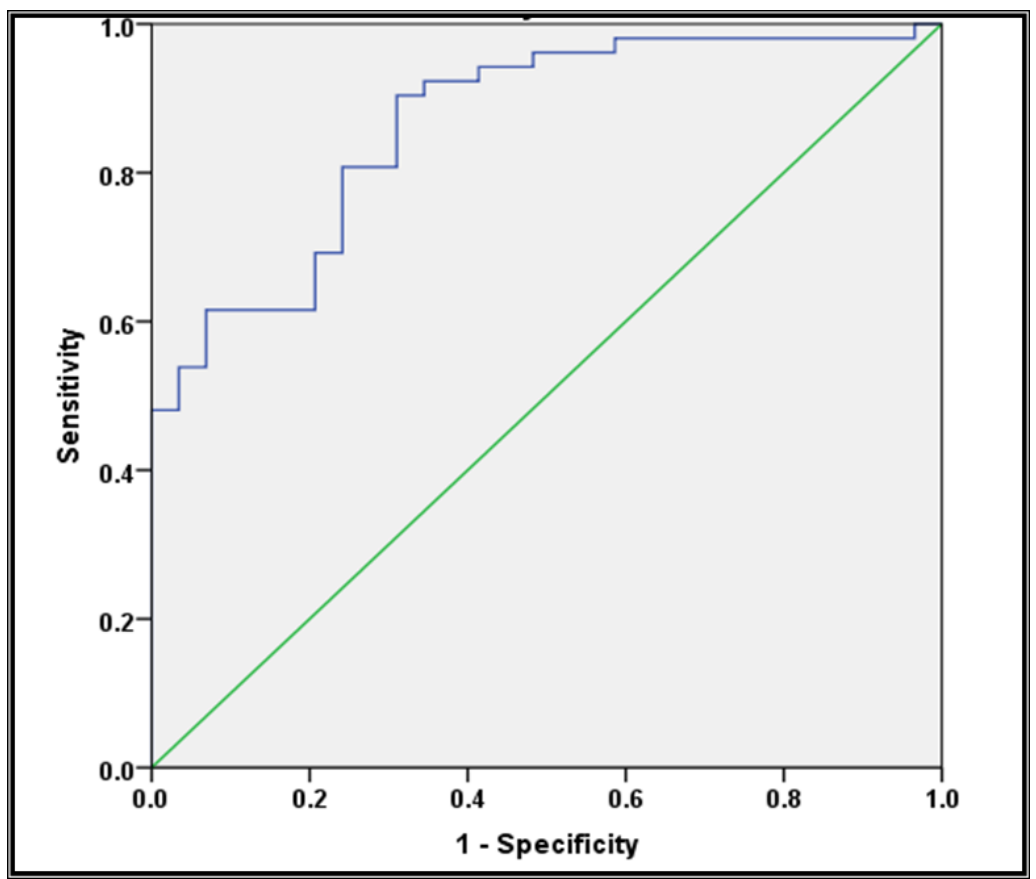

Figure (1): Receiver operative curve analysis of vWF as a predictor for esophageal varices

\section{DISCUSSION}

Results of the present study revealed that vWF values were significantly higher in group I than group II and controls but no significant difference between group II and control group.

These results are supported by that obtained by Ferlitsch et al. who reported that vWF was significantly higher in patients with $\mathrm{PH}$, compared to patients without $\mathrm{PH}$. VWF values were higher in patients with esophageal varices and history of ascites, compared to patients without, higher vWF levels were significantly associated with varices Odds Ratio $(\mathrm{OR})=3.27 ; \mathrm{P}<0.001)$ and ascites $(\mathrm{OR}=3.93 ; \mathrm{P}<0.001)[\mathbf{1 2}]$.

Reuken et al. mentioned that an imbalance of increased vWF levels associated with systemic inflammation superimposed on advanced cirrhosis [13].
It was explained by the fact that, chronic liver disease (CLD) with portal hypertension promotes bacterial translocation and subsequent inflammation leading to endothelium activation $[14,15]$.There is increasing evidence that the deregulated inflammatory response in advanced cirrhosis itself further aggravates portal hypertension in a vicious circle $[16,17]$ and despite an overall correlation of the hepatovenous pressure gradient (HVPG) with vWF [12].

vWF is released by activated endothelial cells and therefore represents an indicator of endothelial cell activation and plays a crucial role in high shear stress depending on primary hemostasis. The endothelium plays a crucial role in many vascular diseases and endothelial dysfunction is a fundamental component of the increased hepatic vascular tone of cirrhotic livers $[4,18]$. 
Activation of thrombocytes and endothelium finally leads to platelet aggregation and, probably, to microthrombotic events. Those events lead to increased portal pressure and furthermore might lead to worsening of fibrosis. As vWF is elevated in liver disease, it might be a key player in establishing liver fibrosis [19].

ROC curve analysis of vWF revealed that, at a cutoff value of $173.8 \mu \mathrm{g} / \mathrm{ml}$; the sensitivity for detection of esophageal varices was $80.8 \%$, specificity $76.0 \%$, positive predictive value (PPV) was $93.9 \%$, negative predictive value (NPV) was 55.6\%; area under the curve was 86.6 denoting good predictive value of $\mathrm{vWF}$ in prediction of esophageal varices. These results are comparable to those reported by Ferlitsch et al. who reported that, the most important finding of their study is that a vWF cutoff at 315 can clearly stratify patients with compensated and decompensated liver cirrhosis [12].

In addition, $\mathrm{Wu}$ et al. reported that, a cutoff values of plasma vWF $(1510.5 \mathrm{mU} / \mathrm{mL}$ and 1701 $\mathrm{mU} / \mathrm{mL}$ ) showed high positive predictive value (PPV, 90.2\% and $87.5 \%$ ) in predicting clinically significant portal hypertension and severe portal hypertension. Cutoff values of vWF (1414 $\mathrm{mU} / \mathrm{ml}$ and $1990 \mathrm{mU} / \mathrm{mL}$, PPV $90.3 \%$ and $86.3 \%$, respectively) were provided to detect the presence and degree of esophageal varices [6].

In addition, Maieron et al. reported that, the diagnostic performance of $\mathrm{vWF}$ predicting liver fibrosis in comparison to other fibrosis scores was analysed by AUROC: with 0.703 , vWF is one of the best markers to differentiate patients with fibrosis (F1-F4) from patients without fibrosis (F0). They concluded that, vWF offer an easy possibility to evaluate the stage of fibrosis to diagnose subclinical cirrhosis in patients with chronic hepatitis C [20].

There was significant positive correlation between vWF and Child, MELD, OV grade and PHG. These results are comparable to those reported by Lisman et al. who reported that, when patients were classified according to MELD score, they also observed a strong correlation between vWF levels and severity of the disease as assessed by the MELD score $(r=0.448, \mathrm{P}<0.001)$ [7]. Lisman et al. also reported that, they added vWF levels were substantially elevated in Child A (488\%), child B (711\%) and child C (735\%) cirrhosis, where in the reference group, the median $\mathrm{vWF}$ propeptide levels was $89 \%(\mathrm{p}<0.001)$. They added, there was positive correlation between vWF and Child classification [7].

Results of the present study are also in agreement with $\mathrm{Wu}$ et al. who reported that, linear correlations were observed between levels of vWF in liver tissues with portal hypertensive gastropathy and esophageal varices severity [6].Consistent with these findings, Mura and colleagues documented that elevated vWF levels were able to predict clinical endpoints even after adjustment for HVPG and liver dysfunction. Also, levels of vWF are increased in patients with cirrhosis and correlate with the severity of liver disease [5].

\section{CONCLUSION}

VWF is significantly increased in cirrhotic patients with esophageal varices; it had a good power of prediction for development of esophageal varices. vWF correlated will with severity of liver cirrhosis assessed by Child and MELD scores as well as OV grade and PHG.

\section{Funding: None}

\section{Conflicts of interest: None}

Ethical Approval: A written informed consent was taken from all included patients, and the study was approved by the Ethical Committee of our institution.

\section{REFERENCES}

1. D'Amico G, Garcia-Tsao G, Pagliaro, L. Natural history and prognostic indicators of survival in cirrhosis: a systematic review of 118 studies. $J$ Hepatol.2006; 44: 217-31.

2. Bosch J, Garcia-Pagan JC, Berzigotti A, Abraldes, JG. Measurement of portal pressure and its role in the management of chronic liver disease.Semin Liver Dis. 2006; 26:348-362.

3. Thabut D, Moreau R, Lebrec D. Non-invasive assessment of portal hypertension in patients with cirrhosis. Hepatology2011; 53:683-694.

4. Iwakiri Y, Groszmann RJ. Vascular endothelial dysfunction in cirrhosis. J Hepatol.2007; 46:92734

5. MuraVL, Reverter JC, Flores-Arroyo A, Raffa S, Reverter E, Seijo S et al. Von Willebrand factor levels predict clinical outcome in patients with cirrhosis and portal hypertension. Gut2011; 60: 1133-8 
6. Wu H, Yan S, Wang G, Cui S, Zhang C, Zhu Q. Von Willebrand factor as a novel noninvasive predictor of portal hypertension and esophageal varices in hepatitis B patients with cirrhosis. Scand $J$ Gastroenterol.2015, 50 (9): 1-10.

7. Lisman T, Bongers TN, Adelmeijer J, Janssen HL, de Maat MP, de Groot PG, Leebeek FW.. Elevated levels of vonWillebrand Factor in cirrhosis support platelet adhesion despite reduced functional capacity. Hepatology2006; 44: 53-61.

8. Pugh RN, Murray-Lyon IM, Dawson JL, Pietroni MC, Williams R. Transection of the esophagus for bleeding esophageal varicies.Br J Surg. 1973; 60:646-49.

9. Kamath PS, Wiesner RH, Malinchoc M, Kremers W, Therneau TM, Kosberg CL et al. "A model to predict survival in patients with end-stage liver disease". Hepatology 2001; 33: 464-70.

10. Sarwar S, Khan AA, Alam A, Butt AK, Shafqat F, Malik K et al. Effect of Band Ligation on Portal Hypertensive Gastropathy and Developmentof Fundal Varices. J. Ayub Med. Coll. AbbottabadPakistan 2006; 18: 32-35.

11. De Franchis R. Updating consensus in portal hypertension: report of the Baveno III Consensus Workshop on definitions, method-logy and therapeutic strategies in portal hypertension. J. Hepatol. 2000; 33:846-852.

12. Ferlitsch M, Reiberger T, Hoke M, Salzl P, Schwengerer B, Ulbrich G, et al. von Willebrand factor as new noninvasive predictor of portal hypertension, decompensation and mortality in patients with liver cirrhosis.Hepatology2012; 56: 1439-47.
13. Reuken PA, Kussmann A, Kiehntopf M, Budde U, et al. Imbalance of von Willebrand factor and its cleaving protease ADAMTS13 during systemic inflammation superimposed on advanced cirrhosis. Liver International 2015; 35(1): 37-45

14. Wiest R, Garcia-Tsao G. Bacterial translocation (BT) in cirrhosis. Hepatology2005; 41(3): 42233.

15. Bruns T, Zimmermann HW, Stallmach A. Risk factors and outcome of bacterial infections in cirrhosis. World J Gastroenterol.2014; 20 (10): 2542-54.

16. Mehta G, Gustot T, Mookerjee RP, Garcia-Pagan JC, Fallon MB, Shah VH et al. Inflammation and portal hypertension - the undiscovered country. $J$ Hepatol.2014; 61: 155-63.

17. Mehta G, Mookerjee RP, Sharma V, Jalan R. Systemic inflammation is associated with increased intrahepatic resistance and mortality in alcohol-related acute-on chronic liver failure. Liver Int. 2014; doi: 10.1111 / liv.12559.

18. Matei V, Rodriguez-Vilarrupla A, Deulofeu R, Colomer D, Fernández M, Bosch J, Garcia-Pagán JC. The eNOS cofactor tetrahydrobiopterin improves endothelial dysfunction in livers of rats with CCl4 cirrhosis. Hepatology2006; 44: 44-52.

19. Iannacone M, Sitia G, Isogawa M, Marchese P, Castro MG, Lowenstein PR et al. Platelets mediate cytotoxic $\mathrm{T}$ lymphocyte-induced liver damage. Nat Med.2005; 11: 1167-9.

20. Maieron A, Salz P, Trauner M, Hametner S. Von Willebr and Factor as a new marker for noninvasive assessment of liver fibrosis and cirrhosis in patients with chronic hepatitis C. Aliment PharmacolTher.2014; 39: 331-338. 